\title{
Identificación de genes de resistencia a antimicrobianos en felinos silvestres: ¿muestra del impacto de las producciones pecuarias en los ecosistemas?
}

Ana Sofía Angulo ${ }^{1}$, Fernando Esperón Fajardo², Roberto Salom-Pérez ${ }^{3}$, Javier Carazo ${ }^{4}$, Francisco Taylor ${ }^{5}$, Edwin Pilé6, Kinndle Blanco-Peña ${ }^{1,7} \otimes$

1 Posgrado Regional en Ciencias Veterinarias, Escuela de Medicina Veterinaria, Universidad Nacional, Heredia, Costa Rica. Email: mvzangulo sofi@yahoo.com, kblanco@una.cr

2 Centro de Investigación en Sanidad Animal (INIA-CISA), Ctra. Algete a El Casar s/n, 28130 Valdeolmos, Madrid, España. Email: esperon@inia.es

3 Panthera, Programa Jaguar, San Pedro, Montes de Oca, Costa Rica. Email: rsalom@panthera.org

4 Consultor independiente. Santo Domingo de Heredia, Costa Rica. Email: carazo.javier@gmail.com

5 Dirección de Gestión Integrada de Cuencas Hidrográficas, Ministerio de Ambiente de Panamá, Albrook, Ciudad de Panamá, Panamá. Email: taylor.francisco@gmail.com

6 Instituto de Investigaciones Científicas y Servicios de Alta Tecnología (INDICASAT), Ciudad del Saber, Clayton, Ciudad de Panamá, Panamá. Email: pileedwin@gmail.com

7 Instituto Regional de Estudios en Sustancias Tóxicas (IRET), Universidad Nacional, Heredia, Costa Rica. Email: kblanco@una.cr

El intercambio ecológico y la viabilidad de la biodiversidad de Costa Rica se ven amenazados por la degradación y la fragmentación del bosque. Esta investigación pretende proponer una herramienta para identificar el posible impacto de las actividades pecuarias sobre áreas de conservación del Caribe. Para ello, se realizó la extracción de ADN de las heces de 14 jaguares (Panthera onca) y 13 pumas (Puma concolor) de vida libre mediante el kit Fujifilm, Fuji. Estas fueron identificadas previamente por individuo y especie, mediante métodos moleculares. Luego, se cuantificaron 16 genes de resistencias a los antimicrobianos (ARGs) (tetA, tet $\mathrm{B}$, tet $\mathrm{C}$, tet $\mathrm{K}$, tet $\mathrm{M}$, tet $\mathrm{Q}$, tet $\mathrm{S}$, tet $\mathrm{W}$ y tet $\mathrm{Y}$, cat I, cat $\mathrm{II}$, sulI, sulII, qnr $\mathrm{S}$, van $\mathrm{A}$ y mec $\mathrm{A}$ ) mediante $\mathrm{qPCR}$. La caracterización de los sitios de muestreo se hizo mediante QGIS y ArGIS, al emplear datos geoespaciales de la región y el censo de SENASA 2014. De los 14 ARGs hallados, $9.3 \%$ tenían una resistencia baja, $16 \%$ intermedia y $13.9 \%$ alta. Los genes tetQ $(85.2 \%)$ y tet $\mathrm{Y}(70.3 \%)$ fueron los más frecuentes, mientras que tetS (11.1 \%) fue el menos usual. Las sulfonamidas (sulI y sulII) ( $70.3 \%$ cada uno), fenicoles (catII y catI) $(18.5 \%$ y $52 \%$, respectivamente) y quinolonas (qnrS) (11\%) presentaron valores representativos. No se identificaron genes de vancomicina $(v a n \mathrm{~A})$ ni meticilina $(\mathrm{mec} \mathrm{A})$. Los jaguares tuvieron más número de $\mathrm{ARGs}(37 \%)$. El Parque Nacional Braulio Carrillo fue el área donde se encontraron las más altas concentraciones de tet, sul y cat. El gen qnrS se identificó, principalmente, fuera de áreas protegidas. De acuerdo con el análisis integral de los datos, el impacto pecuario podría influir sobre la presencia y concentración de ARGs.

凶 Autor para correspondencia Kinndle Blanco-Peña: kblanco@una.cr 